\title{
An Intuitive Approach in Scada Systems by Using Artificial Neural Networks
}

\author{
Cem SEN ${ }^{1}$, Ozhan OZKAN ${ }^{2}$, Burcu ÇARKLI YAVUZ ${ }^{3}$ and Cenk YAVUZ ${ }^{2+}$ \\ ${ }^{1}$ Kocaeli Water and Sewerage Administration, Kocaeli, TURKEY \\ ${ }^{2}$ Dept. of Electrical\&Electronics Eng., Eng. Faculty, Sakarya University, Sakarya, TURKEY \\ ${ }^{3}$ Dept. of Information Sys. Eng., Faculty of Comp. \& Inf. Sci., Sakarya University, Sakarya, TURKEY
}

\begin{abstract}
In the light of technological development, monitoring and control of remote point workstations from a single control center can be an important place in all business areas. SCADA systems can be remote point control and monitoring jobs in business are quite busy and brought convenience and innovation are looking forward is playing an important role in the development of the projection. But in the process of the SCADA systems business problems occurring and that causes disruption of the handle. One of the most important problem is the data communication is dropped. Data transmission in remote point workstation are not intelligent devices (RTU), taking advantage of the learning method of historical data can be found in the system's intuitive approach to business process can continue and the solution to this problem. Intuitive approaches in recent years and use different application areas as well as control technology has been especially used in scada technology new. In this study, the energy sector, scada applications, and especially drinking water distribution networks unmanned operational operations (SCADA systems), see the heuristics approach can be applied to the note were asked to resign.
\end{abstract}

Keywords: an intuitive approach, system, SCADA, artificial neural networks, Matlab, potable water, Network Management

\section{Introduction}

In this study, using the historical data measured and recorded in the General Directorate of Kocaeli Water and Sewerage Administration (ISU) water scada system, which monitors and controls the drinking water distribution network in Kocaeli province, the continuity of the system in cases where the data communication in the SCADA system is interrupted is achieved by means of the learning method based on past data by an intuitive approach. Running $24 / 7$ and as remote station control and tracking unmanned aerial vehicles made in a case where the Scada System communication outages Kocaeli drinking water in time cannot be made as a result the system locking stop water tank flooding (water losses) or remain thirsty people unwanted event and causes the formation of the State. This is the biggest weakness of the scada system is problematic. The aim of this study is as mentioned above; in case of communication failure in scada system communication between stations until or again until legacy data from automation system intervene to continue. Classic systems, supervision control and data acquisition/energy management system applications, wide-area monitoring and control systems, it is important that the basic design. The system was established around the faze units of measurement, measured data center sends a computer; where the dynamic behavior of the system is made available online snapshots. System information about the new quality, voltage, angular or frequency imbalance, thermal overload in case of system stability and oscillations on evaluate and actively requires protect (Zima et al., 2005). A wide range of used multi-layer neural networks has been investigated for use during often encountered problems and solution methods are

\footnotetext{
+ Corresponding author. Tel.: +00905055254276.
}

E-mail address: ozhan@sakarya.edu.tr. 
emphasized. Optimization method for restricting Artificial Neural Networks, a global optimum solution to convergence, especially some genetic algorithm and constraint in cases violating the infeasible solution, to evaluate the results, goal programming method option offers as a solution (Ermis, 2005). Water represents a vital problem for the people. So in the process of water supply wastewater lifting line construction and operation can be monitored on an ongoing basis and in the process can be controlled. Used for this purpose and is an optimum solution for scada systems with energy efficiency and optimum drinking water can be achieved in business and supply (Dobriceanu, 2008) Information and communication technologies can be provided for safety and control of energy distribution network. Power distribution system provides control of the scada systems by utilizing secure against cyber attacks in the name of the get, two thoughtful regard our theoretical approaches based on an intuitive logic (Cembrano et al., 2000).

\subsection{Water SCADA system}

SCADA system, Kocaeli, potable water system, water distribution facilities and drinking water into the water supply in the computer environment is effectively and efficiently controlled. 91 pieces drinking water upgrade Station, 12 pieces drinking water treatment plant, 119 pieces of drinking water water tank, a total of 222 PCs stations, 278 pieces pump, 189 units energy analyzer, 411 pieces water level sensor, 35 pieces input muffler, 206 units output muffler, 152 pieces auma valve, 48 units water quality measurement Analyzer, 92 pieces SSR (liquid level sensor), 81 pieces of pressure gauge (line Pressure Sensor), 57 piece generator scada system by monitoring and controlled automation. Water tanks water levels and volumes; are dependent on water storage and water amounts, printed in an upper level line pressure values promoted and monitored the status of positions from the center of the valve. System according to the water level in the upper levels, water tanks and pumping stations from the Center and bottom levels of the pump and open the valve closes automatically. Hours of operation of the pump motor sequence promoted automatically. SCADA system upgrade stations, motors and valves in the given set value automatic operation while at the same time, switch off the pump energy parameters within the system (Cos Q, active, reactive, capacitive energy consumption values) real time measuring the reactive consumption is provided by minimize penalties arising from. In addition, water quality measuring device with water in the $\mathrm{pH}$, Chlorine, Turbidity measurements made as a snapshot of SCADA are computer monitored and historical records, the quality of water is now the here and now.

\subsection{Operation logic system}

RTU are either taken from the instrument peripherals into real-time data according to the result of the logic software algorithm output within the RTU signals opened valves to stop the work, produced engine events such as closure status and depending on the circumstances and developed are carried out in an automated manner, depending on the scenario. This work with each other on both the station's data communication scenario that is healthy so must be the continuous live data transmission line. Data communication is not a fixed amount and output incoming data before the RTU signals is it somehow remains constant. So even a mouthful of water filled tank motor or motors continue to run or store even after the completion of preconfigured motors will not work.

\section{Materials and Methods}

Kocaeli Municipality 222 stations sanctioned by the General Directorate drinking water the database history data from the Scada system, Scada Systems by utilizing Intuitive Approaches. RTU instrument peripherals into or received from real time data, according to the results output logic software algorithm within the RTU signals is produced; operation of the engine, the valve is opened, the closure of events such as status and automatically, depending on the circumstances.

This work with each other on both the station's data communication algorithm to be healthy, it is needed to have continuous live data transmission line. Data communication is not a fixed amount of data, and preceding the RTU output signals in such a way that it remains constant. Even a mouthful of water filled tank motor or Motors continue to run and preconfigured from the upper tank overflow and water losses caused by them, or even just builds Motors stores will not work. In this case, the people living in that area without water. Data communication can be dropped off the factors; Power outages, this situation with UPS to 
be solved. Hardware problems are the damages occur to antenna, antenna connector or antenna cable. The density of the data transmission network and data transmission caused by silting up of the front early memory, RTU fainting pulse overflow is locked and the status of RTU's.

Signal pollution; in the same frequency band of frequencies is the formation of the publication or harmonic. SCADA systems weaknesses; running 24/7 and unmanned stations, remote control and as a tracker for reasons mentioned above in the scada system made communication outages occurred, cannot be done in time, the system crashes, unwanted event and causes the formation of the State. This is the biggest weakness of the SCADA system is problematic. Based on data from the past to solve this problem by utilizing intuitive approaches are tried to be used. In case of communication failure in SCADA system communication between the stations until or again until the intervention, especially from historical data of the promotion side of the RTU, this promotion printed top water from water tank water push or engines must be stopped or there must be an answer to the question. Because of this system could be operated in the process it's times like that I should be aware of the critical points in the communication outage situations, what then is available to the chance to intervene nor have the chance to get to that location on time, now retired. Therefore, the states of the region remain without water tank flood or fire resistance.

SCADA system computers, up to 5 years can be maintained on all measured parameters, record a snapshot. Data communication for reasons listed above in any way experienced uninterrupted when the preceding the date on which the registered data in the database that match the conditions of the current measuring conditions the engine's operating conditions automatic operation can be resumed. The water tank top Level parameters required Info and water consumption Trend is with air temperature data. This varies depending on the value of the parameter. temperature increases will increase the value of water consumption, water consumption value increases, the water level will show the trend towards a decrease in the trend, so more water will be needed, and in this case at the bottom of the engines, the engine and/or promotion status of their work. In this case, the temperature of the immediate instant communication outage, high up the water tank in water consumption and a snapshot of the current level on the status of the child according to the value of determination in software promotion station motor.

The intuitive approach, old data from RTU using the new results can be achieved. RTU can store much memory so data in memory because it is not logical, this old data. Therefore, the solution with MATLABß and ANN has been considered. History data is taken from the data base on scada system sanctioned by the drinking water. Kocaeli Municipality ISU General Directorate of the two engines operated by one of the engines, if necessary, alternating between the work of one of the Derince Camlik Promotion and this water pressure Camlik Top Store has become. The level information and the water consumption trend of the Derince Camlik Upper water reservoir, which is a upper level water reservoir of the Derince Camlik Promotion Station between 02.04.2014 and 10.04.2014, for use in the training of the ANN from the SCADA System database, 326 pieces of data including the working order of the motors in the pumping station and working time information are used. 18 data are also used for testing. Motor stopping and working hours of the last one in the glass elevation station, main exit of Camlik, RTU temperature information and water level information of this depot were obtained.

Ambient temperature does not have instant and hourly basis, would give an idea about digital temperature, the temperature of the information used by discounting RTU. Engine's stopping and working promotion intervals, upper water level water store, the temperature of the output flow rate in Camlik are collected in RTU network information page. The data is all positive values; MATLAB ${ }^{\circledR}$ LOGSIG function has been selected.

\section{Simulation Results}

A total of 344 training and test data in the 9-day period were regulated after being normalized in the interval of 0-1, converted into matrix format and processed in ANN. ANN is trained with 326 data and tested with 18 data. This study revealed the model in the form of a multilayered feed forward neural network. Input with five parameters and one output parameter to a system by using the best studied and hidden layer designed to result in order to obtain different numbers of neurons with different variations of the input parameter. 
An $=$ Water level $(\mathrm{cm})$ the top Store Derince Camlik

$\mathrm{Bn}=$ Derince Camlik Parent Network Output Instant flow rate $(1 / \mathrm{sec})$

$\mathrm{Cn}=$ Ambient Temperature $\left({ }^{\circ} \mathrm{C}\right)$

Dn $=$ Engine operating and Pause Times $(\mathrm{min})$

En $=$ Engine No.

$\mathrm{KN}=$ Derince Camlik Promotion Engine Cases (work/stop)

They fixed the data that is used to change between each other variations of input parameters, changing the number of entries increasing reduction of neurons increased, reducing the transfer function of as many different variations as a result of his work called the best results given below.

Between 0 and test output matrix have been regarded as 0.49999 the values 0.1 ;

0.5000 is in values from 1 to 0.9 .

An -Entry in the matrix; with the function Tansig with transacted 10 Neurons

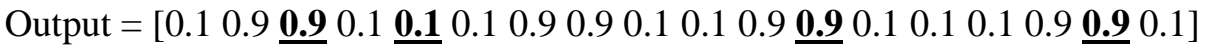

Test Output Matrix $=\left[\begin{array}{lllllllll}0.31804 & 0.8922 & \underline{\mathbf{0 . 2 7 8 8 6}} & 0.10029 & \underline{\mathbf{0 . 5 0 5 7 3}} & 0.49396 & 0.81425 & 0.57082 & 0.10029\end{array}\right.$

$0.278860 .8922 \underline{\mathbf{0 . 3 8 6 7 9}} 0.100290 .10890 .378240 .8922 \underline{\mathbf{0 . 4 1 1 8 3}} 0.10029]$

4 from 18 test data output data is incorrect. $\mathbf{7 7 . 7 7 \%}$ Success.

An-Bn -Entry in the matrix; with the function Tansig with transacted 10 Neurons

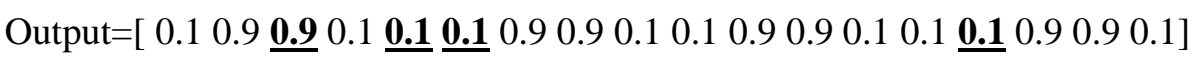

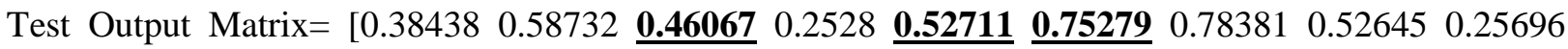
$0.49720 .792540 .533780 .21820 .40059 \underline{\mathbf{0 . 5 8 4 0 8}} 0.797940 .537420 .22128]$

4 from 18 test data output data is incorrect. $\mathbf{7 7 . 7 7 \% \text { Success }}$

An-Bn-Cn- Entry in the matrix; with the function Tansig with transacted 10 Neurons

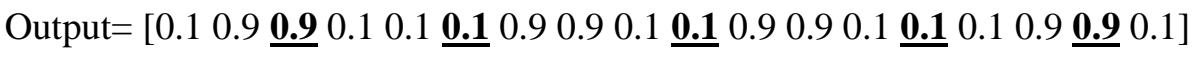

Test Output Matrix $=\left[\begin{array}{lllllllll}0.45546 & 0.77973 & \underline{\mathbf{0 . 3 5 0 4}} & 0.14329 & 0.40631 & \underline{\mathbf{0 . 6 0 9 5 8}} & 0.80911 & 0.61617 & 0.14063\end{array}\right.$ $\underline{\mathbf{0 . 6 9 8 6}} 0.858560 .552560 .12882 \underline{\mathbf{0 . 5 3 5 0 5}} 0.196160 .84324 \underline{\mathbf{0 . 1 9 6 6}} 0.1538]$

5 from 18 test data output data is incorrect $\mathbf{\% 7 2 , 2 2 \text { Success }}$

An-Bn-Cn-Dn -Entry in the matrix; with the function Tansig with transacted 10 Neurons

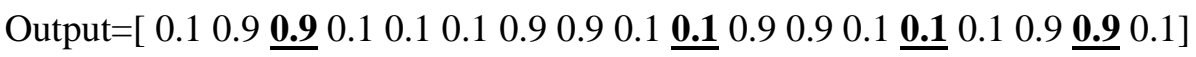

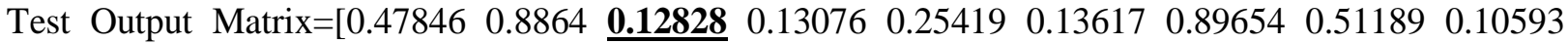
$\underline{\mathbf{0 . 6 0 4 0 9}} 0.814570 .688570 .10594 \underline{\mathbf{0 . 5 5 0 3 5}} 0.100510 .84973 \underline{\mathbf{0 . 4 4 8 9 1}} 0.126]$

4 from 18 test data output data is incorrect. $77.77 \%$ Success

An-Bn-Cn-Dn-En Entry in the matrix; with the function Tansig with transacted 10 Neurons

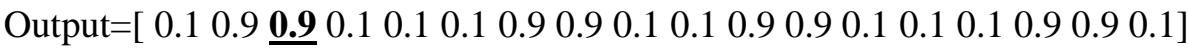

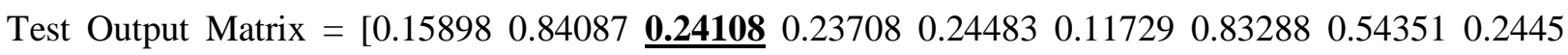

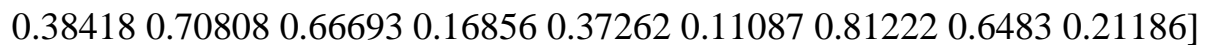

1 from 18 test data output data is incorrect. $\underline{\mathbf{\% 9 4 , 4 4} \text { Success }}$

5 and 1 looping over a system designed to create input and output variables of the model worked and studied a representation of the system are below.

Studies and introduction to ANNs when keep trying different variations; 2 inlet (An-Dn Inlet) ANNs is also 5 Inlet (An-Bn-Cn-Dn-En-Input) matrix has been found in the same successful result given.

An-Dn -Entry in the matrix; with the function Tansig with transacted 10 Neurons

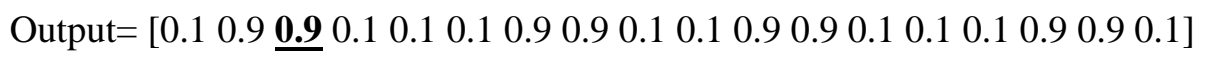




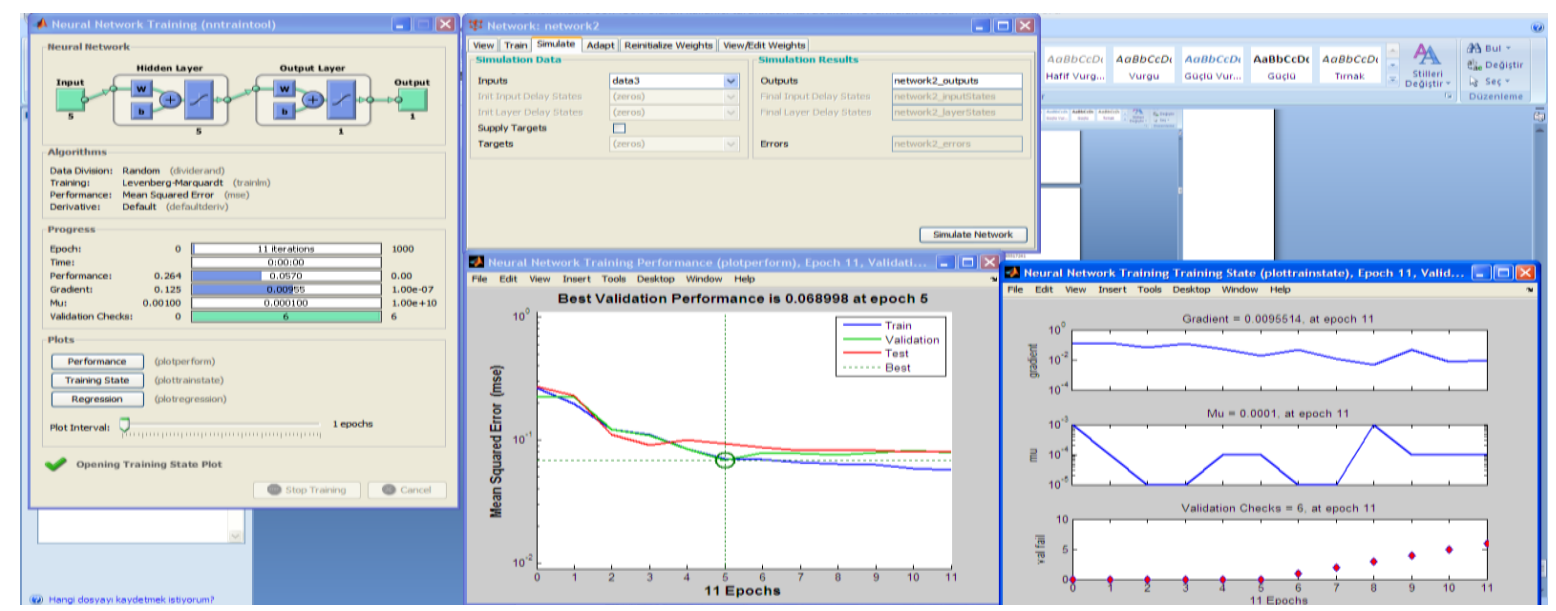

Fig. 1: Input and output structure of ANN, approach values and results of training

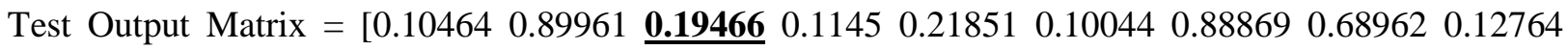
0.246680 .89980 .645220 .144630 .365320 .10 .899680 .595110 .12762 ]

1 from 18 test data output data is incorrect. \%94, 44 Success

2 input and 1 looping over a system designed and worked on model input and output variables, and it is attempted to create a representation of the system studied is given below.

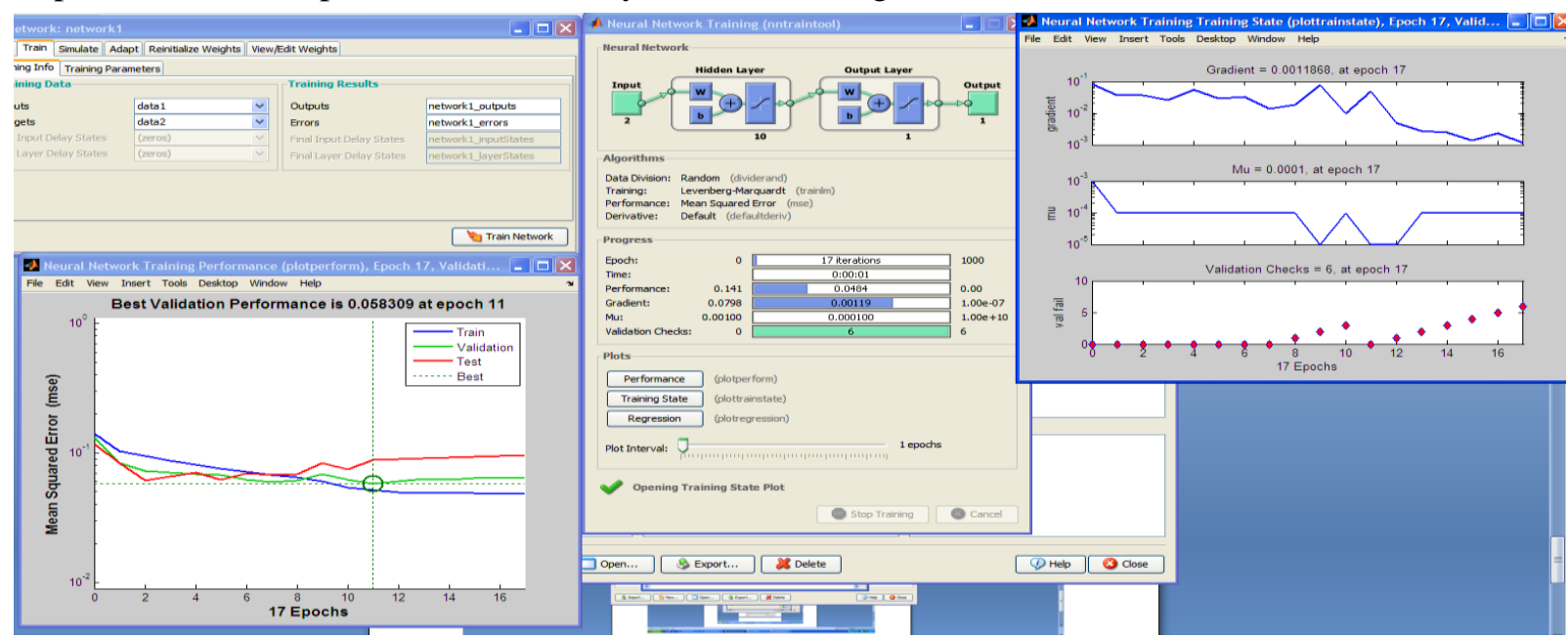

Fig. 2: Input and output structure of ANN, approach values and results of training

\section{Conclusions}

In this study, as a result of the intuitive approach created, it has been found that the water losses in the water reservoirs, which cannot be controlled and monitored by the SCADA due to communication breaks, are reduced to a minimum, such as the dehydration of people living in that area. This research is funded by the Coordination Unit of Scientific Research Projects of Sakarya University (Project number: 2017-01-00-006).

\section{References}

[1] Cembrano, G., Wells, G., Quevedo, J., Pérez, R., \& Argelaguet, R. (2000).Optimal control of a water distribution network in a supervisory control system. Control engineering practice, 8:(10), 1177-1188

[2] Dobriceanu, M., Bitoleanu A., Popescu M., Enache S., \& Subtırelu E. (2008). SCADA System for Monitoring Water Supply Networks. WSEAS Transactions on Systems, Volume: 7, Issue: 10, 1070-1079.

[3] Ermis, M. (2014). Logistics Systems Modeling With Artificial Neural Networks, Implementation and Control, Ph.D Thesis, Istanbul Technical University Institute Of Science And Technology.

[4] Zima, M., Larsson, M., Korba, P., Rehtanz, C., \& Andersson, G. (2005), Design Aspects For Wide-Area Monitoring and Control Systems. 